
\title{
28 Research Square \\ Electric Scooter - An Alternative Mode of Transportation for Malaysian Youth
}

\section{Abdullah Al Mamun ( $\nabla$ mamun7793@gmail.com )}

Associate Professor, Department of Management Studies, Faculty of Business, UCSI University, Kuala Lumpur, Malaysia. https://orcid.org/0000-0002-9713-742X

Noor Raihani Zainol

Universiti Malaysia Kelantan

Naeem Hayat

Universiti Malaysia Kelantan Kampus Pengkalen Chepa: Universiti Malaysia Kelantan

\section{Original article}

Keywords: Environmental Concern, Knowledge, Theory of Planned Behaviour, Attributes of Interest, Monetary Benefit, Willingness to Purchase, Electric Scooter

Posted Date: November 4th, 2020

DOI: https://doi.org/10.21203/rs.3.rs-100232/v1

License: (1) (1) This work is licensed under a Creative Commons Attribution 4.0 International License. Read Full License 


\section{Abstract}

Background: This study examined the effect of environmental concern, knowledge, attitude, subjective norms, perceived behavioural control, attributes of interest, and monetary benefit on the willingness to purchase and actual purchase of electric scooter (ES) among Malaysian youth. This study adopted a cross-sectional design and collected quantitative data from 1,306 youth by sharing a Google form link through social media.

Results: The findings reveal that environmental concern and environmental knowledge have a significant positive effect on attitude towards ES. Findings also show that attitude towards ES, subjective norms, perceived behavioural control, attributes of interest, and monetary benefit have a significant positive effect on the willingness to purchase and actual purchase of ES. Findings reveal the positive and significant mediating effect of attitude towards ES and the willingness to purchase ES. The multi-group analysis revealed that the effect of attitude towards willingness was significantly higher among the urban respondents. Moreover, the effect of environmental concern on attitude towards ES among rural respondents was significantly higher than urban respondents. In contrast, the effect of environmental knowledge on attitude towards ES among urban respondents was significantly higher than rural respondents.

Conclusions: The environmental and transportation policymakers should focus on highlighting the attributes of ESs and their environmental and monetary benefits to promote the mass adoption of ESs among Malaysian youth. Offering subsidies like no road tax and zero import duty and reducing the production of combustion-based two-wheelers are among the options to facilitate the adoption of ES among Malaysian youth. The adoption of ES is socially promoted to reduce the use of conventional twowheelers. Another relevant area that needs attention is the charging outlet or fuel stations for ES. The adoption of ES remains low if there is a lack of charging or fuel stations.

\section{Introduction}

Global individual mobility is increasing at the turn of the century, and fossil fuels remain the core energy instrument that drives the world (Eccarius \& Lu, 2020). Global transport significantly contributes to anthropogenic climate change. The contribution of the transport sector is about $23 \%$ of the global greenhouse gases (GHGs) emissions (Tu \& Yang, 2019). Road transport accounts for more than $73 \%$ of the total of GHGs emissions from the transport sector (DellaValle \& Zubaryeva, 2019). Urban areas suffer from transport-related air pollution and low emitting vehicles from early 2000. Cities like Jakarta, Bangkok, and Kuala Lumpur are known as hubs of motorbike users (Eccarius \& Lu, 2020). Motorbikes offer flexibility and economy in highly congested cities with ease of operation and maintenance. However, the GHGs emissions are high in the conventional combustion-based motorcycles engines that are currently used across the globe (Tu \& Yang, 2019). 
Moving towards green vehicles can address the situation and significantly reduce the GHGs from the transport sector. The global effort in reducing the GHGs emission from the transport sector can foster the efforts to offer electric vehicles (EV) (Lai, Liu, Sun, Zhang \& Xu, 2015). Electromobility is the solution to address GHGs and reduce noise and local air pollution due to the use of conventional internal combustion-based engines (Peters \& Dutschke, 2014). The increasing prices of fuels motivate the reduction of using conventional internal combustion-based engines. EV use is promoted by the government across the globe. The reduced registration or no road tax for EV encourages consumers to buy EVs and promote the idea of reducing GHGs (Carley, Krause, Lane \& Graham, 2013).

\subsection{Using Electric Scooter}

Achieving sustainable society starts with the adoption of a sustainable lifestyle at an individual level. Individual mobility is a critical topic in developed and developing societies. An individual becomes mobile, and the environment pays the price of enhanced individual mobility (Eccarius \& Lu, 2020). However, individual mobility is the key to the economy, leisure or holiday pursuits. About $25 \%$ of the GHGs emissions are caused by transportation (Peters \& Dutschke, 2014). EV intensively reduces individual mobility impact on the environment. ES is the critical individual vehicle that is currently utilised in developed countries (Carley et al., 2013). Like other EVs, ESs can reduce GHGs emissions with low noise besides having elegant design and shape (Eccarius \& Lu, 2020). However, the ES is in its early market stage, and general consumers' acceptance of ES is low. About 1.7 billion of the scooters (two-wheeler) are owned by individuals around the globe (Chen et al., 2018). However, there are fewer shares of ES. ES runs on electric charger or batteries (Eccarius \& Lu, 2020). The rise in the purchase of ESs is observed in recent times, but it is not enough to significantly reduce GHGs from individual mobility (Higueras-Castillo, Molinilo, Cosa-Stefaniak \& Liebana-Cabanillias, 2019). A total of $80 \%$ of the globally registered twowheelers are owned by Asians, and South East Asia has the highest number of two-wheeler owners in Indonesia, Taiwan, and Malaysia (Eccarius \& Lu, 2020).

Having an individual mobility vehicle is on the rise in recent times, and it caused an increase in GHGs emissions (Leavy, Drossinos \& Thiel, 2017). Southeast Asians are known for having a higher number of two-wheelers in the world due to the general tendency of the population to own two-wheelers (Jone, Cherry, Vu \& Nguyen, 2013). In Malaysia, the adoption rate is still at its infancy stage among Malaysians. Consumer awareness and lack of government support reduce the penetration of ES in Malaysia.

Government support may help to have clean air and less population from transport besides achieving the sustainable development goals (SDGs) 7,11 , and 15 . This study aims to explore the willingness to purchase and actual purchase of ESs among Malaysian youth using the theory of planned behaviours (TPB) and extending the TPB by perceived monetary benefits and perceived attributes of interest for ES. Malaysian youth can play an essential role in reducing the effect of mobility by adopting ES.

The following section of the paper discusses the relevant literature and development of the hypotheses. Then, it is followed by summaries of the method, analysis, and results of the study. The following section offers the discussion and conclusion of the study. 


\section{Literature Review}

\section{LITERATURE REVIEW}

\subsection{Theory of Planned Behaviour}

TBP is well-known, and it is one of the apparent theories for social science that deals with the behavioural intention and adoption of environment-friendly practices and products (Lai et al., 2015). Behavioural intention is a significant predictor of the behaviour or adoption behaviour for environmental practices or products (Maichum, Parichatnon \& Peng, 2016). Moreover, behavioural intention is the outcome for the social-cognitive factors of attitude, subjective norm and perceived behavioural control (Afroz, Masud, Akthar, Islam \& Duasa, 2015; Yadav \& Pathak, 2016).

TPB is used in different studies to explore the adoption of green products by the customers' intention to buy green products like hydrogen-electric motorcycles food (Chen, Tsai \& Hsieh, 2018), green product purchase intention (Mostafa, 2006), and payment behaviour for environment-friendly products among low-income groups (Yadav \& Pathak, 2016; 2017). This study extended the TPB in the ecological business adoption like beekeeping and extended the application and predictive power of the TPB framework for the adoption of green business.

\subsection{Factors Affecting Attitude towards Electric Scooters 2.2.1. Environmental Concern (ENC)}

The concern for anything can trigger some appropriate actions to solve the issues at hand. ENC is the individual's perception that his or her actions have consequences on the environment (Yadav \& Pathak, 2017). ENC is a kind of evaluative acceptance that one's and other's behaviours can affect the environment (Maichum et al., 2016). An individual with a higher level of concern for the environment is more likely to embrace or participate in environmentally friendly practices or adopt green products. Yadav and Pathak (2016) stated that ENC significantly predicts the environmental attitude of purchasing ecofriendly products. Moreover, Maichum et al. (2016) claim that consumers' ENC $(\beta=0.342, p=0.050)$ stimulates green consumption by impacting the environmental attitude among Thai consumers. Therefore, this study postulated the following hypothesis:

Hypothesis $\left(\mathrm{H}_{1}\right)$ : Environmental concern has a significant positive effect on the attitude towards ES among Malaysian youth.

\subsubsection{Environmental Knowledge (ENK)}

ENK provides the base to develop an attitude towards green behaviours (Mostafa, 2006). ENK is the general awareness of the facts, concepts, and relationships concerning the natural environment with the ecosystem (Mostafa, 2016). ENK develops a personal understanding of the environment, and it is about the vital association between environmental aspects and impact (Yadav \& Pathak, 2016). ENK can lead to the appreciation of the collective responsibility to achieve a sustainable lifestyle (Lai et al., 2015). 
Individual environmental action depends on the concrete understating of environmental issues that can lead to environmental actions. The lack of ENK significantly reduces environmental actions. Mostafa (2006) reported that the individual ENK significantly leads to $(\beta=0.563, p=0.000)$ green product purchase intention among the Egyptian sample. Therefore, this study hypothesised the following:

Hypothesis $\left(\mathrm{H}_{2}\right)$ : Environmental knowledge has a significant positive effect on the attitude towards ES among Malaysian youth.

\subsection{Factors Affecting the Willingness to Purchase Electric Scooter}

\subsubsection{Attitude towards Electric Scooters (ATT)}

Attitude reveals the psychological assessment of the product or service (Yadav \& Pathak, 2016). TPB particularly deals with the attitude towards the behaviour. Attitude exposes the subjective evaluation of the given object based on the summary assessment (Maichum et al., 2016). For green products, the attitude towards green products or services are greatly influenced by the subjective internal assessment of the environmental products and initiated the internal stimuli to own the product (Lai et al., 2015). Mostafa (2006) stated the positive influence of the attitude of green products on the purchase intention among Egyptian consumers. However, Yadav and Pathak (2017) reported that ATT significantly ( $\beta=$ $0.350, p=0.001)$ influences the intention to purchase green products among the poor. Hence, this study hypothesised the following:

Hypothesis $\left(\mathrm{H}_{3}\right)$ : Attitude towards ESs has a significant positive effect on the willingness to purchase ES among Malaysian youth.

\subsubsection{Subjective Norms (SBN)}

Social pressures play a significant role in the development of the intention to behave in a particular manner (Lai et al., 2015). Subjective norm is the perceived social pressure stimulation to perform or not to perform a specific behaviour. Individual decision making is influenced by the perceived social norm of important people (Carley et al., 2013). Maichum et al. (2016) stated that SBN influences $(\beta=0.307, p=$ 0.050 ) the intention of purchasing green products among Thai consumers. Hence, this study hypothesised the following:

Hypothesis $\left(\mathrm{H}_{4}\right)$ : Subjective norms have a significant positive effect on the willingness to purchase ES among Malaysian youth.

\subsubsection{Perceived Behavioural Control (PBC)}

Individual perception and ability can affect the performance of the behaviour (Yadav \& Pathak, 2017). PBC is the perception of ease or difficulty for the performance of a specific behaviour (Maichum et al., 2016). PBC is the vital ingredient of the TPB. PBC controls the intention to adopt green products and services among individuals (Yadav \& Pathak, 2017). Lai et al. (2015) stated that PBC is the perceptual 
cues about the intention to use green products. Yadav and Pathak (2017) stated that the effect of PBC ( $\beta$ $=0.315, p=0.001$ ) on the purchase intention for green products is significant among the poor residents of India. Hence, this study proposed the following hypothesis:

Hypothesis $\left(\mathrm{H}_{5}\right)$ : Perceived behavioural control has a significant positive effect on the willingness to purchase ES among Malaysian youth.

\subsubsection{Electric Scooter's Attributes of Interest (AIO)}

Electric vehicles are associated with the unique attributes of the fuel economy besides given the incentives from the government (DellaValle \& Zubaryeva, 2019). ESs are lightweight and easy to drive than conventional scooters (Eccarius \& Lu, 2020). Appearance and safety are the two significant attributes that attract consumers towards EVs (Afroz et al., 2015). The economic advantage of registration and reduction in road tax for the EVs can lure young consumers into purchasing ESs (Razak, Yusaf, Mashahadi, Alias \& Othaman, 2014). Carley et al. (2013) stated that the attributes of interest facilitate the intention to adopt EVs among US citizens. Hence, the following hypothesis is proposed:

Hypothesis $\left(\mathrm{H}_{6}\right)$ : Attributes of interest have a significant positive effect on the willingness to purchase ES among Malaysian youth.

\subsubsection{Perceived Monetary Benefit (PMB)}

Adoption as a personal decision is influenced by the perception of monetary benefits from the adoption of the product or practice (Peters \& Dutschke, 2014). A consumer may consider converting to a new green product based on the reduced running cost of the product or the economic benefits of using the new innovative product (Tu \& Yang, 2019). Lai et al. (2015) reported that the PMB from the use of electric vehicles $(\beta=0.435, p=0.000)$ influences the intention to purchase electric vehicles among Chinese respondents. Reduced fuel consumption and incentives associated with the purchase of electric vehicles promote the intention to purchase electric vehicles (Razak et al., 2014). This study proposed the following hypothesis:

Hypothesis $\left(\mathrm{H}_{7}\right)$ : Perceived monetary benefit has a significant positive effect on the willingness to purchase ES among Malaysian youth.

\subsubsection{Willingness to Purchase Electric Scooter (WTP)}

Positive willingness to purchase or the intention to behave in a particular manner can lead to the performance of the behaviour. The critical evidence was available on the willingness as the critical precursor of the purchase behaviour. Yadav and Pathak (2017) postulated that the intention to purchase green products $(\beta=0.563, p=0.001)$ significantly influences the purchase of green products among Indian respondents. Therefore, this study proposed the following hypothesis:

Hypothesis $\left(\mathrm{H}_{8}\right)$ : Willingness to purchase ES has a significant positive effect on the actual purchase of ES among Malaysian youth. 


\subsection{Mediating Effect of Attitude towards Electric Scooters}

TPB directs that the attitude towards a specific behaviour significantly influences the intention towards a specific behaviour (Yadav \& Pathak, 2017). Moreover, the attitude is impacted by individual environmental concerns and environmental knowledge. Attitude towards green products significantly mediates the individual environmental concern and willingness to purchase eco-friendly products (Maichum et al., 2016). The relationship between environmentally friendly products and the willingness to purchase is mediated by the attitude towards environmentally friendly products (Yadav \& Pathak, 2017). Thus, this study hypothesised the following:

Hypothesis $\left(\mathrm{H}_{1 \mathrm{M}}\right)$ : Attitude towards ESs mediates the effect of environmental concern on the willingness to purchase ESs among Malaysian youth.

Hypothesis $\left(\mathrm{H}_{2 \mathrm{M}}\right)$ : Attitude towards ESs mediates the effect of environmental knowledge on the willingness to purchase ESs among Malaysian youth.

\subsection{Mediating Effect of the Willingness to Purchase Electronic Sooter}

TPB postulates that the willingness mediates the relationship between the predictors, i.e., attitude towards behaviour, subjective norm, and perceived behavioural control for the particular behaviour (Yadav \& Pathak, 2017). However, Lai et al. (2015) reported that behavioural intention is mediated by the factors of TPB and the actual environment-friendly product buying behaviour. Moreover, this study expanded the TPB by factors for the attributes of interest and monetary benefits for the purchase of ES. Therefore, this study hypothesised the following:

Hypothesis $\left(\mathrm{H}_{3 \mathrm{M}}\right)$ : Willingness to purchase ESs mediates the effect of attitude towards ESs on the purchase of ESs among Malaysian youth.

Hypothesis $\left(\mathrm{H}_{4 \mathrm{M}}\right)$ : Willingness to purchase ES mediates the effect of subjective norms on the purchase of ESs among Malaysian youth.

Hypothesis $\left(\mathrm{H}_{5 \mathrm{M}}\right)$ : Willingness to purchase ES mediates the effect of perceived behavioural control on the purchase of ESs among Malaysian youth.

Hypothesis $\left(\mathrm{H}_{6 \mathrm{M}}\right)$ : Willingness to purchase ES mediates the effect for the attributes of interest on the purchase of ESs among Malaysian youth.

Hypothesis $\left(\mathrm{H}_{\mathrm{M}}\right)$ : Willingness to purchase ES mediates the effect of monetary benefit on the purchase of ESs among Malaysian youth.

\section{Research Methodology}


This study adopted the cross-sectional design and collected quantitative data from Malaysian youth through an online survey to examine the effect of environmental concern, knowledge, attitude, subjective norms, perceived behavioural control, attributes of interest, and monetary benefit on the willingness to purchase and actual purchase of ES among Malaysian youth. Figure 1 shows all hypothesised and tested associations.

\subsection{Population and Sample}

The target population of this study were Malaysian youth (aged between 15-40). In order to collect the data about the willingness and purchase of ES, this study adopted the cross-sectional design and collected data through an online survey during the first two weeks of April 2020. This study designed a Google form, highlighted the purpose and reporting procedure of the study, and collected informed consent from all respondents before they participated in the survey. The questionnaire was distributed by sharing the link of the questionnaire form using social media. A total of 1,306 valid responses were yielded for the study.

\subsection{Measurement and Scales}

Explicit and straightforward statements were designed to gauge responses for the constructs. This approach could obtain an appropriate and accessible understanding of the respondents. Five questions measured the environmental concern were adopted from several studies (Bennett \& Vijaygopal, 2018; Maichum, Parichatnon \& Peng, 2016). Five questions were adopted from several studies to measure environmental knowledge (Maichum, Parichatnon \& Peng, 2016; Mostafa, 2006). Five questions measured the attitude towards the ES were adopted from several studies (Bennett \& Vijaygopal, 2018; Afroz et al., 2015; Maichum, Parichatnon \& Peng, 2016). Five questions were adopted from several studies to measure subjective norm (Bennett \& Vijaygopal, 2018; Maichum, Parichatnon \& Peng, 2016). Five questions measured perceived behavioural control were adopted from Maichum, Parichatnon, and Peng (2016). Five questions measured ES's attributes of interest were adopted from Carley et al. (2013). Five questions measured perceived monetary benefits were adopted from Lai et al. (2015). Four questions measured the willingness to purchase ES were adopted from Bennett and Vijaygopal (2018).

\subsection{Assessment of Common Method Variance (CMV)}

Social science research methods are connected with common method biases that are initiated by the use of single source and single point of time data collection technique (Podsakoff, Mackenzie Lee \& Podsakoff, 2003). Harman's (1976) one-factor test proposed a strategy to access the impact of CMV on study constructs (Podsakoff et al., 2003). The use of one-factor Harman's test confirmed that CMV was not a critical issue for the study as the highest factor accounted for $36.71 \%$ variance, which was less than the suggested limit of $50 \%$ (Podsakoff et al., 2003).

\subsection{Multivariate Normality}


SEM-PLS is not associated with multivariate normality in the data as it is a non-parametric analysis instrument (Hair, Risher, Sarstedt \& Ringle, 2019). However, multivariate data normality was suggested by Peng and Lai (2012) on the use of web power (https://webpower.psychstat.org/wiki/tools/index) to confirm data normality. The test results confirm that the data set is not as normal as Mardia's multivariate coefficient p-values that is less than 0.05 (Cain, Zhang \& Yuan, 2017).

\subsection{Data Analysis Method}

Partial least squares structural equation modelling (PLS-SEM) with the Smart-PLS software 3.1 was exploited to examine the study data. PLS-SEM is a multivariate analysis instrument to assess path models that have latent constructs (Hair et al., 2019). PLS-SEM allows scholars to work with non-normal and small data sets. Furthermore, the casual-predictive nature of the PLS-SEM can work with complex models that have composites and without the assumption of goodness-of-fit estimation than the covariance-based SEM (Chin, 2010). Two-step techniques were proposed to analyse data with PLS-SEM, and the first measurement was performed on the model to test the reliability and validity of study constructs (Hair et al., 2019). The second stage was performed with the structural model associations and study hypotheses with significance levels (Chin, 2010). The model estimation was performed with $r^{2}$, $Q^{2}$, and the effect size $f^{2}$ that describe the path effect from the exogenous construct for the endogenous construct (Hair et al., 2019).

PLSpredict is recommended by Shmueli, Sarstedt, Hair, Cheah, Ting, Vaithilingham, and Ringle (2019) to validate the model's key endogenous construct and examine prediction errors. Predictive performance is evaluated by the mean of $\mathrm{Q}^{2}$ predict statistic for the verification with the naïve yardstick that is designed by PLSpredict method (Shmueli et al., 2019). PLSpredict estimates the naïve benchmark in the linear regression model (LM). Then, a comparison between RMSE or MAE values for LM and PLS model confirms the explanatory power of two methods. Shmueli et al. (2019) suggest that the PLS-SEM model lacks predictive power if the PLS-SEM model yields higher prediction errors than the LM benchmark. If the majority of the PLS-SEM analysis produces higher prediction errors than the LM benchmark, it depicts the low predictive power of the PLS-SEM model. If only a small portion of the PLS-SEM analysis produces higher prediction errors than the LM benchmark, it indicates the medium power of the PLS-SEM model. If there is no indicator in the PLS-SEM model on more errors than the LM benchmark, the PLS-SEM model has higher predictive power (Shmueli et al., 2019).

The importance-performance map analysis (IPMA) defines the study constructs into relatively high to low by importance and performance for the endogenous construct (Chin, 2010). IPMA detects the possible area of enhancements that necessitate contemplation from policymakers and scholars. IPMA analysis is built on the total effect of rescaled variables scores in the unstandardised procedure (Ringle \& Sarstedt, 2016). Rescaling can settle for each latent variable score that is between 0 and 100 . The mean value of the latent variable score signifies the performance of latent variable, where 0 represents the least and 100 represents the most significant in the performance of the endogenous construct (Hair et al., 2019). 
Furthermore, multi-group analysis (MGA) in PLS-SEM allows scholars to differentiate the variances in predefined groups (Henseler, Ringle \& Sinkovics, 2009). MGA is an agile method to evaluate the variances between the groups inside the data set (Hair et al., 2014). MGA supports the investigators to assess the variations among the structural paths of various groups in the data (Hair et al., 2019). The first step is to generate groups based on the categorical variables of interest like age, gender, or income. Then, the path coefficients of the groups are analysed, and the two groups are significantly diverse from each other based on the guidelines by Henseler et al. (2009). The differences that exist within the data set are based on the characteristics that may not be evident in aggregated data, and the path coefficients of the group data can demonstrate the statistical variance using MGA to establish the differences that are statistically significant among the data based on categorical bases (Henseler et al., 2009).

\section{Data Analysis}

\subsection{Demographic Characteristics}

The data were collected from the majority of the respondents who were female (59.3\%). A total of $23.2 \%$ of the respondents were below 21 years old. The majority of the respondents were between 21-25 years old $(61.7 \%)$. Respondents between $26-30$ years old were $8.9 \%, 31-35$ years were $2 \%$, and the remaining were $36-40$ years. The majority of the respondents were single (92.3\%), and the remaining were married. The following are the percentage for education level: the majority of the respondents completed their bachelor's degree or equivalent (49.5\%), secondary school level (19.3\%), diploma or technical school level (28.5\%), master level (2.5\%), and the remaining completed their doctoral level. The following are the percentage for income: monthly income of less the RM2,500 (76.1\%), income between RM2,501-RM5,000 (16.3\%), income between RM5,001-RM7,500 (4.2\%), income between RM7,501-RM10,000 (1.8\%), and the remaining have an income of more than RM10,000. The majority of the respondents live in urban areas (87.8\%). The following are the percentage for the place of origin: Chinese origin (74.6\%), Malaysian (6.3\%), Indian origin (5.4\%), and other origins (13.7\%). About $88.3 \%$ of respondents do not have ES, and the remaining respondents have ES. 
Table 1

Demographic Characteristics

\begin{tabular}{|c|c|c|c|c|c|}
\hline & $\mathbf{N}$ & $\%$ & & $\mathbf{N}$ & $\%$ \\
\hline Gender & & & Marital Status & & \\
\hline Male & 531 & 40.7 & Single & 1206 & 92.3 \\
\hline Female & 775 & 59.3 & Married & 96 & 7.4 \\
\hline \multirow[t]{2}{*}{ Total } & 1306 & 100.0 & Divorced & 4 & 0.3 \\
\hline & & & Total & 1306 & 100.0 \\
\hline \multicolumn{6}{|l|}{ Age Group } \\
\hline Below 21 years & 303 & 23.2 & Education & & \\
\hline $21-25$ years & 806 & 61.7 & Secondary school certificate & 252 & 19.3 \\
\hline $26-30$ years & 116 & 8.9 & Diploma/technical school certificate & 372 & 28.5 \\
\hline $31-35$ years & 26 & 2.0 & Bachelor degree or equivalent & 646 & 49.5 \\
\hline $36-40$ years & 55 & 4.2 & Master's degree & 32 & 2.5 \\
\hline \multirow[t]{2}{*}{ Total } & 1306 & 100.0 & Doctoral degree & 4 & 0.3 \\
\hline & & & Total & 1306 & 100.0 \\
\hline \multicolumn{6}{|l|}{ Ethnicity } \\
\hline Malay & 82 & 6.3 & Household Income & & \\
\hline Chinese & 974 & 74.6 & Below RM2500 & 994 & 76.1 \\
\hline Indian & 71 & 5.4 & RM2501-RM5000 & 213 & 16.3 \\
\hline Others & 179 & 13.7 & RM5001-RM7500 & 55 & 4.2 \\
\hline \multirow[t]{2}{*}{ Total } & 1306 & 100.0 & RM7501-RM10,000 & 23 & 1.8 \\
\hline & & & RM10,001-RM12500 & 9 & 0.7 \\
\hline Living Areas & & & More than RM12500 & 12 & 0.9 \\
\hline Urban & 1147 & 87.8 & Total & 1306 & 100.0 \\
\hline Rural & 159 & 12.2 & & & \\
\hline \multirow[t]{3}{*}{ Total } & 1306 & 100.0 & $E S$ & & \\
\hline & & & No ES & 1153 & 88.3 \\
\hline & & & Have ES & 153 & 11.7 \\
\hline
\end{tabular}




\begin{tabular}{|c|c|c|c|}
\hline $\mathbf{N}$ & $\%$ & $\mathbf{N}$ & $\%$ \\
\hline & Total & 1306 & 100.0 \\
\hline
\end{tabular}

\subsection{Reliabilities and Validities}

The reliabilities for the study's latent constructs can be achieved and appraised by Cronbach's alpha (CA), DG rho, and composite reliability (CR) (Hair et al., 2019). The CA values for each construct are above the threshold of 0.70 , and the minimum value of CA value is 0.789 (Chin, 2010). The results are reported in Table 2. Furthermore, all DG rho values are above the threshold of 0.70 , where the minimum value of DG rho is 0.796 (Hair et al., 2019). Moreover, CR values are beyond the threshold of 0.70 , where the minimum value of $C R$ value is 0.856 (Chin, 2010). These results signify that the latent constructs have achieved adequate reliabilities and performed well for the subsequent analysis. The AVE for all items for each construct must be above 0.50 score to confirm convergent validity (Hair et al., 2019). The items display that the constructs have acceptable convergent validity (see Table 2.). All the VIF values for each construct are below the threshold of 3.3., displaying no issue of multicollinearity (Chin, 2010). The item loading and cross-loading are reported for the construct discriminant validity in Tables 3 and 4 , respectively.

Table 2

Reliability and Validity

\begin{tabular}{|c|c|c|c|c|c|c|c|c|}
\hline Variables & No. Items & Mean & SD & $\mathrm{CA}$ & DG rho & CR & AVE & VIF \\
\hline ENC & 5 & 5.178 & 0.815 & 0.789 & 0.796 & 0.856 & 0.546 & 1.404 \\
\hline ENK & 5 & 4.886 & 0.987 & 0.854 & 0.856 & 0.895 & 0.630 & 1.404 \\
\hline ATT & 5 & 5.200 & 0.985 & 0.883 & 0.884 & 0.914 & 0.682 & 1.916 \\
\hline SBN & 5 & 4.444 & 1.210 & 0.925 & 0.928 & 0.943 & 0.769 & 2.108 \\
\hline PBC & 5 & 4.658 & 1.137 & 0.893 & 0.895 & 0.921 & 0.700 & 2.706 \\
\hline $\mathrm{AOI}$ & 5 & 5.084 & 0.950 & 0.805 & 0.815 & 0.865 & 0.564 & 2.059 \\
\hline PMB & 5 & 4.991 & 0.987 & 0.817 & 0.818 & 0.873 & 0.579 & 1.958 \\
\hline WTP & 4 & 4.980 & 1.147 & 0.919 & 0.919 & 0.943 & 0.805 & 1.000 \\
\hline PES & 1 & 0.117 & 0.322 & 1.000 & 1.000 & 1.000 & 1.000 & \\
\hline \multicolumn{9}{|c|}{$\begin{array}{l}\text { Note: ENC.: Environmental Concern; ENK.: Environmental Knowledge, ATT: Attitude towards ESs; } \\
\text { SBN.: Subjective Norms; PBC.: Perceived Behavioural Control; AOI.: ES's Attributes of Interest; PMB: } \\
\text { Perceived Monetary Benefit; WTP.: Willingness to Purchase ES; PES: Purchased ES; SD: Standard } \\
\text { Deviation; CA: Cronbach's Alpha; DG rho - Dillon-Goldstein's rho; CR - Composite Reliability; AVE - } \\
\text { Average Variance Extracted; VIF - Variance Inflation Factors }\end{array}$} \\
\hline
\end{tabular}

\section{Source}


Author's data analysis

Table 3

Discriminant Validity

\begin{tabular}{|c|c|c|c|c|c|c|c|c|c|}
\hline & ENC & ENK & ATT & SBN & PBC & AOI & PMB & WTP & PES \\
\hline \multicolumn{10}{|c|}{ Fornell-Larcker Criterion } \\
\hline ENC & 0.739 & & & & & & & & \\
\hline ENK & 0.536 & 0.794 & & & & & & & \\
\hline ATT & 0.479 & 0.460 & 0.826 & & & & & & \\
\hline SBN & 0.255 & 0.438 & 0.514 & 0.877 & & & & & \\
\hline PBC & 0.318 & 0.435 & 0.587 & 0.714 & 0.837 & & & & \\
\hline $\mathrm{AOI}$ & 0.402 & 0.340 & 0.590 & 0.489 & 0.618 & 0.751 & & & \\
\hline PMB & 0.348 & 0.366 & 0.589 & 0.486 & 0.579 & 0.620 & 0.761 & & \\
\hline WTP & 0.371 & 0.365 & 0.626 & 0.551 & 0.639 & 0.616 & 0.661 & 0.897 & \\
\hline PES & -0.017 & 0.053 & 0.059 & 0.133 & 0.172 & 0.064 & 0.094 & 0.070 & 1.000 \\
\hline \multicolumn{10}{|c|}{ Heterotrait-Monotrait Ratio (HTMT) } \\
\hline ENC & - & & & & & & & & \\
\hline ENK & 0.667 & - & & & & & & & \\
\hline ATT & 0.573 & 0.526 & - & & & & & & \\
\hline SBN & 0.305 & 0.493 & 0.565 & - & & & & & \\
\hline PBC & 0.384 & 0.496 & 0.656 & 0.781 & - & & & & \\
\hline $\mathrm{AOI}$ & 0.509 & 0.407 & 0.698 & 0.547 & 0.713 & - & & & \\
\hline PMB & 0.435 & 0.439 & 0.693 & 0.559 & 0.679 & 0.764 & - & & \\
\hline WTP & 0.439 & 0.411 & 0.694 & 0.594 & 0.704 & 0.712 & 0.763 & - & \\
\hline PES & 0.058 & 0.057 & 0.071 & 0.139 & 0.182 & 0.098 & 0.106 & 0.073 & - \\
\hline
\end{tabular}

\section{Source}

Author's data analysis 
All the study constructs have suitable discriminant validities (see Table 3). Furthermore, the FornellLarcker criterion (1981) and HTMT ratio were employed to evaluate the discriminant validity of study constructs. The Fornell-Larcker criterion was estimated with the square root of the respective construct's $\mathrm{AVE}$, and the square root of AVE for the construct must be higher than the correlation among other constructs (Hair et al., 2019). HTMT ratio needs to be less than 0.90 to establish discriminant validity for each construct (Henseler et al., 2015). Tables 3 and 4 show that the study has discriminant validity for each construct. 
Table 4

Loadings and Cross-Loading

\begin{tabular}{|c|c|c|c|c|c|c|c|c|c|}
\hline Code & ENC & ENK & ATT & SBN & PBC & $\mathrm{AOI}$ & PMB & WTP & PES \\
\hline ENC1 & 0.755 & 0.412 & 0.356 & 0.195 & 0.220 & 0.265 & 0.261 & 0.270 & 0.014 \\
\hline ENC2 & 0.790 & 0.454 & 0.357 & 0.224 & 0.253 & 0.277 & 0.285 & 0.291 & -0.027 \\
\hline ENC3 & 0.795 & 0.321 & 0.390 & 0.121 & 0.199 & 0.317 & 0.257 & 0.272 & -0.082 \\
\hline ENC4 & 0.723 & 0.284 & 0.355 & 0.136 & 0.203 & 0.342 & 0.235 & 0.272 & -0.010 \\
\hline ENC5 & 0.614 & 0.542 & 0.305 & 0.287 & 0.315 & 0.285 & 0.249 & 0.269 & 0.059 \\
\hline ENK1 & 0.427 & 0.788 & 0.319 & 0.351 & 0.343 & 0.234 & 0.283 & 0.264 & 0.033 \\
\hline ENK2 & 0.463 & 0.775 & 0.347 & 0.312 & 0.300 & 0.255 & 0.290 & 0.281 & 0.050 \\
\hline ENK3 & 0.464 & 0.813 & 0.394 & 0.305 & 0.324 & 0.248 & 0.295 & 0.311 & 0.002 \\
\hline ENK4 & 0.397 & 0.803 & 0.382 & 0.377 & 0.397 & 0.317 & 0.319 & 0.294 & 0.073 \\
\hline ENK5 & 0.381 & 0.790 & 0.375 & 0.392 & 0.359 & 0.289 & 0.264 & 0.292 & 0.052 \\
\hline ATT1 & 0.423 & 0.411 & 0.835 & 0.372 & 0.466 & 0.504 & 0.477 & 0.497 & 0.010 \\
\hline ATT2 & 0.450 & 0.397 & 0.843 & 0.427 & 0.506 & 0.485 & 0.471 & 0.538 & 0.087 \\
\hline ATT3 & 0.415 & 0.348 & 0.813 & 0.288 & 0.370 & 0.474 & 0.469 & 0.446 & -0.022 \\
\hline ATT4 & 0.361 & 0.341 & 0.859 & 0.482 & 0.523 & 0.501 & 0.524 & 0.559 & 0.069 \\
\hline ATT5 & 0.326 & 0.398 & 0.776 & 0.541 & 0.546 & 0.469 & 0.489 & 0.536 & 0.090 \\
\hline SBN1 & 0.218 & 0.377 & 0.448 & 0.850 & 0.592 & 0.393 & 0.415 & 0.445 & 0.139 \\
\hline SBN2 & 0.224 & 0.386 & 0.465 & 0.888 & 0.601 & 0.423 & 0.426 & 0.471 & 0.093 \\
\hline SBN3 & 0.213 & 0.394 & 0.438 & 0.901 & 0.620 & 0.439 & 0.417 & 0.456 & 0.113 \\
\hline SBN4 & 0.200 & 0.388 & 0.416 & 0.885 & 0.632 & 0.411 & 0.419 & 0.483 & 0.144 \\
\hline SBN5 & 0.255 & 0.374 & 0.480 & 0.860 & 0.673 & 0.468 & 0.448 & 0.547 & 0.097 \\
\hline PBC1 & 0.255 & 0.378 & 0.509 & 0.652 & 0.817 & 0.487 & 0.464 & 0.537 & 0.160 \\
\hline PBC2 & 0.306 & 0.376 & 0.534 & 0.585 & 0.838 & 0.550 & 0.485 & 0.584 & 0.115 \\
\hline PBC3 & 0.247 & 0.374 & 0.497 & 0.637 & 0.864 & 0.514 & 0.491 & 0.529 & 0.151 \\
\hline PBC4 & 0.249 & 0.341 & 0.459 & 0.582 & 0.841 & 0.517 & 0.491 & 0.521 & 0.159 \\
\hline
\end{tabular}

Note: ENC.: Environmental Concern; ENK.: Environmental Knowledge, ATT: Attitude towards ESs; SBN.: Subjective Norms; PBC.: Perceived Behavioural Control; AOI.: ES's Attributes of Interest; PMB: Perceived Monetary Benefit; WTP.: Willingness to Purchase ES; PES: Purchased ES. (2) The Italic values in the matrix above are the item loadings, and others are cross-loadings 


\begin{tabular}{|llllllllll|}
\hline Code & ENC & ENK & ATT & SBN & PBC & AOI & PMB & WTP & PES \\
\hline PBC5 & 0.267 & 0.347 & 0.448 & 0.527 & 0.823 & 0.512 & 0.492 & 0.498 & 0.136 \\
AOI1 & 0.321 & 0.285 & 0.477 & 0.456 & 0.553 & 0.764 & 0.460 & 0.509 & 0.048 \\
AOI2 & 0.313 & 0.262 & 0.494 & 0.472 & 0.553 & 0.799 & 0.522 & 0.522 & 0.072 \\
\hline AOI3 & 0.297 & 0.276 & 0.419 & 0.350 & 0.438 & 0.783 & 0.459 & 0.438 & 0.049 \\
\hline AOI4 & 0.266 & 0.238 & 0.417 & 0.361 & 0.464 & 0.778 & 0.475 & 0.454 & 0.104 \\
\hline AOI5 & 0.320 & 0.208 & 0.398 & 0.139 & 0.260 & 0.618 & 0.402 & 0.372 & -0.056 \\
\hline PMB1 & 0.346 & 0.261 & 0.533 & 0.270 & 0.395 & 0.524 & 0.680 & 0.498 & -0.004 \\
\hline PMB2 & 0.209 & 0.297 & 0.393 & 0.444 & 0.468 & 0.479 & 0.724 & 0.472 & 0.087 \\
\hline PMB3 & 0.258 & 0.292 & 0.463 & 0.404 & 0.491 & 0.449 & 0.823 & 0.518 & 0.106 \\
\hline PMB4 & 0.250 & 0.275 & 0.408 & 0.361 & 0.407 & 0.444 & 0.793 & 0.489 & 0.086 \\
\hline PMB5 & 0.258 & 0.266 & 0.438 & 0.370 & 0.440 & 0.462 & 0.777 & 0.532 & 0.080 \\
\hline WTP1 & 0.318 & 0.294 & 0.573 & 0.499 & 0.562 & 0.550 & 0.612 & 0.895 & 0.047 \\
\hline WTP2 & 0.327 & 0.327 & 0.569 & 0.506 & 0.584 & 0.535 & 0.598 & 0.915 & 0.063 \\
\hline WTP3 & 0.339 & 0.347 & 0.552 & 0.515 & 0.603 & 0.563 & 0.593 & 0.914 & 0.086 \\
\hline WTP4 & 0.349 & 0.341 & 0.553 & 0.456 & 0.545 & 0.565 & 0.569 & 0.864 & 0.053 \\
\hline PES & -0.017 & 0.053 & 0.059 & 0.133 & 0.172 & 0.064 & 0.094 & 0.070 & 1.000 \\
\hline Note: ENC.: Environmental Concern; ENK.: Environmental Knowledge, ATT: Attitude towards ESs; \\
SBN.: Subjective Norms; PBC.: Perceived Behavioural Control; AOI.: ES's Attributes of Interest; PMB: \\
Perceived Monetary Benefit; WTP.: Willingness to Purchase ES; PES: Purchased ES. (2) The Italic \\
values in the matrix above are the item loadings, and others are cross-loadings & & \\
\hline
\end{tabular}

\section{Source}

Author's data analysis

\subsection{Path Analysis}

After realising the acceptable reliabilities and validities from the structural evaluation of the model, the next measurement assessment was performed to investigate the study hypothesis. The adjusted $r^{2}$ value for two exogenous constructs (i.e., ENC and ENK) on the attitude towards ES explains the per cent 28.7 of change in the attitude towards ES. The predictive relevance $\left(\mathrm{Q}^{2}\right)$ value for the part of the model is 0.193 , indicating a medium predictive relevance (Chin, 2010). The adjusted $r^{2}$ value for the five exogenous constructs (i.e., ATT, SBN, PBC, AOI, and PMB) on WTP elucidates the per cent 58.6 of change in WTP of ES. The predictive relevance $\left(Q^{2}\right)$ value for the part of the model is 0.469 , indicating a high predictive 
relevance (Chin, 2010). The adjusted $r^{2}$ value for the one exogenous construct (i.e., WTP) on PES explicates the per cent 0.4 of change in the purchase of ES. The predictive relevance $\left(Q^{2}\right)$ value for the part of the model is 0.003 , indicating no predictive relevance (Chin, 2010).

Table 5. Path Coefficients

\begin{tabular}{|c|c|c|c|c|c|c|c|c|c|c|}
\hline Нуро & & Beta & CI - Min & CI - Max & $t$ & $p$ & $r^{2}$ & $f^{2}$ & $\mathrm{Q}^{2}$ & Decision \\
\hline \multicolumn{11}{|c|}{ Factors affecting Attitude towards ESs } \\
\hline $\mathrm{H}_{1}$ & ENC è ATT & 0.326 & 0.278 & 0.374 & 11.123 & 0.000 & 0.287 & 0.106 & 0.193 & Accept \\
\hline $\mathrm{H}_{2}$ & ENK è ATT & 0.285 & 0.235 & 0.335 & 9.442 & 0.000 & & 0.081 & & Accept \\
\hline \multicolumn{11}{|c|}{ Factors affecting Willingness to Purchase ES } \\
\hline $\mathrm{H}_{3}$ & ATT è WTP & 0.206 & 0.155 & 0.256 & 6.701 & 0.000 & & 0.054 & & Accept \\
\hline $\mathrm{H}_{4}$ & SBN è WTP & 0.096 & 0.044 & 0.147 & 3.066 & 0.001 & & 0.011 & & Accept \\
\hline $\mathrm{H}_{5}$ & PBC è WTP & 0.188 & 0.121 & 0.256 & 4.606 & 0.000 & 0.586 & 0.032 & 0.469 & Accept \\
\hline $\mathrm{H}_{6}$ & AOI è WTP & 0.152 & 0.104 & 0.201 & 5.187 & 0.000 & & 0.027 & & Accept \\
\hline $\mathrm{H}_{7}$ & PMB è WTP & 0.290 & 0.235 & 0.346 & 8.620 & 0.000 & & 0.104 & & Accept \\
\hline \multicolumn{11}{|c|}{ Factor affecting the Purchase of ES } \\
\hline $\mathrm{H}_{8}$ & WTP è PES & 0.070 & 0.030 & 0.109 & 2.925 & 0.002 & 0.004 & 0.005 & 0.003 & Accept \\
\hline
\end{tabular}

Note: ENC.: Environmental Concern; ENK.: Environmental Knowledge, ATT: Attitude towards ESs; SBN.: Subjective Norms; PBC.: Perceived Behavioural Control; AOI.: ES's Attributes of Interest; PMB: Perceived Monetary Benefit; WTP.: Willingness to Purchase ES; PES: Purchased ES

Source: Author's data analysis

Table 5 shows the model standardised path values, $t-v a l u e s$, and significance level. The path coefficient between ECN and ATT ( $\beta=0.326, t=11.123, p=0.000)$ indicates a significant and positive effect of environmental concern on the attitude towards ESs. This result forms significant statistical support for $\mathrm{H} 1$. The path value for ENK and ATT $(\beta=0.285, t=9.442, p=0.000)$ shows the influence of environmental knowledge for the attitude towards ES that is positive and significant; hence, it offers significant statistical support for $\mathrm{H} 2$. The path between ATT and WTP $(\beta=0.206, \mathrm{t}=6.701, p=0.000)$ shows the influence of attitude towards ESs in influencing the willingness to purchase ESs that is positive and significant; hence, it supports H3. The path coefficient for SBN and WTP $(\beta=0.096, t=3.066, p=0.001)$ shows a positive and significant effect; it supports $H 4$. The path between PBC and WTP $(\beta=0.188, t=$ 4.606, $p=0.000$ ) shows the influence of PBC in influencing WTP ESs that is positive and significant; it supports H5. The path coefficient for ATI and WTP $(\beta=0.152, t=5.187, p=0.000)$ shows a positive and significant effect; it supports H6. The path between PMB and WTP $(\beta=0.290, t=8.620, p=0.000)$ shows the influence of perceived monetary benefits in influencing the willingness to purchase ESs that is positive and significant; it supports H7. The path coefficient for WTP and PES $(\beta=0.070, t=2.925, p=$ 0.002) shows a positive and significant effect; it supports H8. Table 5 shows the path coefficients.

\subsection{Mediation Analysis}

The mediation effect of the attitude towards ES was tested with $\mathrm{H}_{1 \mathrm{M}}$ for the relationship between ENC and WTP. The result reveals that the attitude towards ES mediates the relationship between ENC and WTP 
$(\beta=0.067, \mathrm{Cl} \min =0.048, \mathrm{Cl} \max =0.086, p=0.000)$, and it supports $\mathrm{H}_{1 \mathrm{M}}$. and $\mathrm{H}_{2 \mathrm{M}}$ for the relationship between ENK and WTP that is mediated by ATT. The result shows that the attitude towards ESs mediates the relationship between ENK and WTP $(\beta=0.059, \mathrm{Cl} \min =0.041, \mathrm{Cl} \max =0.076, p=0.000)$, and it supports $\mathrm{H}_{2 M}$. In $\mathrm{H}_{3 \mathrm{M} \text {, }}$ the relationship between ATT and PES is mediated by WTP. The result shows that WTP mediates the relationship between ATT and PES $(\beta=0.014, \mathrm{Cl} \min =0.006, \mathrm{Cl} \max =0.023, p=$ 0.004), and it supports $\mathrm{H}_{3 \mathrm{M}}$. For $\mathrm{H}_{4 \mathrm{M}}$, the relationship between SBN and PES is mediated by WTP. The result reveals that WTP mediates the relationship between SBN and PES $(\beta=0.007, \mathrm{Cl} \min =0.001, \mathrm{Cl}$ $\max =0.012, p=0.020$ ), and it supports $\mathrm{H}_{4 \mathrm{M}}$. For $\mathrm{H}_{5 \mathrm{M}}$, the relationship between PBC and PES is mediated by WTP. The result reveals that WTP mediates the relationship between PBC and PES $(\beta=0.013, \mathrm{Cl}$ min $=$ $0.004, \mathrm{Cl} \max =0.022, p=0.010$ ), and it supports $\mathrm{H}_{5 \mathrm{M}}$. For $\mathrm{H}_{6 \mathrm{M}}$, the relationship between Al and PES is mediated by WTP. The result reveals that WTP mediates the relationship between Al and PES $(\beta=0.011$, $\mathrm{Cl} \min =0.004, \mathrm{Cl} \max =0.017, p=0.005)$, and it supports $\mathrm{H}_{6 \mathrm{M}}$. For $\mathrm{H}_{7 \mathrm{M}}$, the relationship between $\mathrm{MV}$ and PES is mediated by WTP. The result reveals that WTP mediates the relationship between MV and PES ( $\beta$ $=0.020, \mathrm{Cl} \min =0.008, \mathrm{Cl} \max =0.032, p=0.003)$. The mediation results are presented in Table 7 .

Table 7. Mediating Effects

\begin{tabular}{llcccccc}
\hline Hypo & Associations & Beta & CI - Min & CI - Max & $t$ & $p$ & Decision \\
\hline $\mathrm{H}_{1 \mathrm{M}}$ & ENC è ATT è WTP & 0.067 & 0.048 & 0.086 & 5.871 & 0.000 & Accept \\
$\mathrm{H}_{2 \mathrm{M}}$ & ENK è ATT è WTP & 0.059 & 0.041 & 0.076 & 5.603 & 0.000 & Accept \\
$\mathrm{H}_{3 \mathrm{M}}$ & ATT è WTP è PES & 0.014 & 0.006 & 0.023 & 2.701 & 0.004 & Accept \\
$\mathrm{H}_{4 \mathrm{M}}$ & SBN è WTP è PES & 0.007 & 0.001 & 0.012 & 2.057 & 0.020 & Accept \\
$\mathrm{H}_{5 \mathrm{M}}$ & PBC è WTP è PES & 0.013 & 0.004 & 0.022 & 2.326 & 0.010 & Accept \\
$\mathrm{H}_{6 \mathrm{M}}$ & AOI è WTP è PES & 0.011 & 0.004 & 0.017 & 2.557 & 0.005 & Accept \\
$\mathrm{H}_{7 \mathrm{M}}$ & PMB è WTP è PES & 0.020 & 0.008 & 0.032 & 2.783 & 0.003 & Accept \\
\hline
\end{tabular}

Note: ENC.: Environmental Concern; ENK.: Environmental Knowledge, ATT: Attitude towards ESs; SBN.: Subjective Norms; PBC.: Perceived Behavioural Control; AOI.: ES's Attributes of Interest; PMB: Perceived Monetary Benefit; WTP.: Willingness to Purchase ES; PES: Purchased ES

Source: Author's data analysis

\subsection{Multiple Group Analysis}

Multiple group analyses were executed to match the results for different groups based on gender, living area, and education. One non-parametric test was employed to evaluate the differences in the vital association between the model based on the gender, areas of living, and education. Table 8 shows the path values for two groups with the differences within groups and the p-values as recommended by Henseler et al. (2009). $P_{M G A}$ represents the $p$-values that are achieved using the multiple group analysis of PLS-SEM as the measure for the significance of the difference between the groups (Henseler et al., 2009).

Table 8. Multi-group Analysis 


\begin{tabular}{|c|c|c|c|c|c|c|c|}
\hline & \multicolumn{2}{|c|}{ Male } & \multicolumn{2}{|c|}{ Female } & \multicolumn{2}{|c|}{ Difference } & \multirow[b]{2}{*}{ Decision } \\
\hline & Beta & $p$-value & Beta & $p$-value & Beta & $p$-value & \\
\hline ENC è ATT & 0.244 & 0.000 & 0.173 & 0.000 & 0.071 & 0.129 & No Difference \\
\hline ENK è ATT & 0.130 & 0.007 & 0.171 & 0.000 & -0.041 & 0.268 & No Difference \\
\hline ATT è WTP & 0.304 & 0.000 & 0.353 & 0.000 & -0.049 & 0.229 & No Difference \\
\hline SBN è WTP & 0.255 & 0.000 & 0.297 & 0.000 & -0.042 & 0.259 & No Difference \\
\hline PBC è WTP & 0.204 & 0.000 & 0.171 & 0.001 & 0.033 & 0.338 & No Difference \\
\hline AOI è WTP & 0.256 & 0.000 & 0.318 & 0.000 & -0.062 & 0.188 & No Difference \\
\hline PMB è WTP & 0.097 & 0.018 & 0.099 & 0.013 & -0.002 & 0.491 & No Difference \\
\hline \multirow[t]{3}{*}{ WTP è PES } & 0.090 & 0.007 & 0.046 & 0.068 & 0.044 & 0.181 & No Difference \\
\hline & \multicolumn{2}{|c|}{ Urban } & \multicolumn{2}{|c|}{ Rural } & \multicolumn{2}{|c|}{ Difference } & \\
\hline & Beta & $p$-value & Beta & $p$-value & Beta & $p$-value & Decision \\
\hline ENC è ATT & 0.320 & 0.000 & 0.387 & 0.000 & -0.068 & 0.209 & No Difference \\
\hline ENK è ATT & 0.282 & 0.000 & 0.296 & 0.000 & -0.014 & 0.438 & No Difference \\
\hline ATT è WTP & 0.228 & 0.000 & 0.006 & 0.461 & 0.221 & 0.002 & Sig. Difference \\
\hline SBN è WTP & 0.083 & 0.005 & 0.233 & 0.007 & -0.150 & 0.069 & No Difference \\
\hline PBC è WTP & 0.186 & 0.000 & 0.190 & 0.038 & -0.004 & 0.497 & No Difference \\
\hline AOI è WTP & 0.149 & 0.000 & 0.201 & 0.005 & -0.052 & 0.258 & No Difference \\
\hline PMB è WTP & 0.281 & 0.000 & 0.345 & 0.000 & -0.064 & 0.209 & No Difference \\
\hline \multirow[t]{3}{*}{ WTP è PES } & 0.057 & 0.019 & 0.130 & 0.025 & -0.074 & 0.155 & No Difference \\
\hline & \multicolumn{2}{|c|}{ Secondary School Certificate } & \multicolumn{2}{|c|}{ Bachelor Degree or Equivalent } & \multicolumn{2}{|c|}{ Difference } & \\
\hline & Beta & $p$-value & Beta & $p$-value & Beta & $p$-value & Decision \\
\hline ENC è ATT & 0.220 & 0.003 & 0.385 & 0.000 & -0.165 & 0.031 & Sig. Difference \\
\hline ENK è ATT & 0.452 & 0.000 & 0.237 & 0.000 & 0.216 & 0.011 & Sig. Difference \\
\hline ATT è WTP & 0.233 & 0.003 & 0.217 & 0.000 & 0.016 & 0.429 & No Difference \\
\hline SBN è WTP & 0.014 & 0.437 & 0.109 & 0.003 & -0.095 & 0.159 & No Difference \\
\hline PBC è WTP & 0.136 & 0.096 & 0.139 & 0.003 & -0.004 & 0.478 & No Difference \\
\hline AOI è WTP & 0.219 & 0.002 & 0.182 & 0.000 & 0.037 & 0.325 & No Difference \\
\hline PMB è WTP & 0.311 & 0.000 & 0.290 & 0.000 & 0.020 & 0.411 & No Difference \\
\hline WTP è PES & 0.056 & 0.178 & 0.033 & 0.172 & 0.023 & 0.381 & No Difference \\
\hline
\end{tabular}

Note: ENC.: Environmental Concern; ENK.: Environmental Knowledge, ATT: Attitude towards ESs; SBN.: Subjective Norms; PBC.: Perceived Behavioural Control; AOI.: ES's Attributes of Interest; PMB: Perceived Monetary Benefit; WTP.: Willingness to Purchase ES; PES: Purchased ES

Source: Author's data analysis

\subsubsection{Effects of Gender on the Groups}

The results of the two groups are based on the gender of the sample. The gender has no significant difference in the relationship of the model. The variance of gender does not influence the relationship between study models. The results are depicted in Table 8.

\subsubsection{Effects of Living Area on the Groups}

The results of the two groups are based on the living area of the sample. The living area shows a significant difference in the relationship between ATT and WTP for ES. The urban respondents have more ATT in influencing WTP for ES. However, the variance of the living area (i.e., urban and rural respondents) does not influence the variance between the study's other paths. Study results are provided in Table 8 .

\subsubsection{Effects of Education on the Groups}


The results of the two groups are based on the education of the sample. Education has a significant difference in the relationship between ECN and ATT, ENK, and ATT for ES. The variance of education does not influence the variance between the study's other paths. Analysis results are shown in Table 8.

\subsection{Importance Performance Matrix}

Table 9 shows the outcomes of IPMA. ECN is the most vital cause in the performance of PES (0.326; 73.083), followed by ATT $(0.206 ; 70.001)$, AOI $(0.152,67.674)$, and PMB $(0.290 ; 66.742)$.

Table 9

Performance and Total Effects

\begin{tabular}{|lll|}
\hline Target Construct & \multicolumn{2}{l|}{ Purchase of ES } \\
\hline Variables & Total Effect & Performance \\
\hline Environmental Concern & 0.326 & 73.083 \\
\hline Environmental Knowledge & 0.285 & 64.886 \\
\hline Attitude towards ESs & 0.206 & 70.001 \\
\hline Subjective Norms & 0.096 & 57.468 \\
\hline Perceived Behavioural Control & 0.188 & 61.028 \\
\hline ES's Attributes of Interest & 0.152 & 67.674 \\
\hline Perceived Monetary Benefit & 0.290 & 66.742 \\
\hline Willingness to Purchase ES & 0.070 & 66.333 \\
\hline Source: Author's data analysis & & \\
\hline
\end{tabular}

\subsection{Predictive Assessment}

The sample predictive power of the model was estimated with the PLS $S_{\text {Predict }}$ with ten folds and one repetition. This assessment establishes the performance of the PLS model with new predictive observations. The distribution of error is presented in Fig. 3. Most of the endogenous constructs' indicators outperform the naïve benchmark (Shmueli et al., 2019). The $Q^{2}$ predict value is above 0 . Then, the prediction error is analysed in detail to evaluate the relevant prediction statistic. The error distribution plots show that the error distribution for all items of WTP (Fig. 3) is not highly non-symmetric (Shmueli et al., 2019). Therefore, this study assessed the predictive power based on the RMSE value. The error distribution for PES is highly non-symmetric, and this study used the mean absolute error (MAE) values to assess the predictive power based on PES.

Table 10. Predictive Model Assessment 


\begin{tabular}{cccccc}
\hline & Q $\square_{\text {Predict }}$ & RMSE (PLS-SEM) & RMSE (LM) & Difference & Predictive Power \\
\hline WTP1 & 0.446 & 0.947 & 0.935 & 0.013 & \\
WTP2 & 0.449 & 0.970 & 0.968 & 0.002 & Medium Predictive Power \\
WTP3 & 0.466 & 0.941 & 0.947 & -0.006 & \\
WTP4 & 0.421 & 0.949 & 0.953 & -0.003 & \\
\hline & Q $\square_{\text {Predict }}$ & MAE (PLS-SEM) & MAE (LM) & & \\
\hline PES & 0.009 & 0.206 & 0.206 & 0.000 & No Predictive Power \\
\hline
\end{tabular}

Note: ENC.: Environmental Concern; ENK.: Environmental Knowledge, ATT: Attitude towards ESs; SBN.: Subjective Norms; PBC.: Perceived Behavioural Control; AOI.: ES's Attributes of Interest; PMB: Perceived Monetary Benefit; WTP.: Willingness to Purchase ES; PES: Purchased ES; MAE: Mean Absolute Error; RMSE: Root Mean Squared Error; PLS-SEM: Partial Least Squares - Structural Equation Modelling; LM: Linear Regression Model

Source: Author's data analysis

This study compared the root mean squared error (RMSE) values from the PLS-SEM analysis with the naïve LM benchmark, and it reveals that the PLS-SEM analysis produces equal prediction errors for two cases out of four cases. The results show that the study model has medium predictive power for WTP. The naïve LM benchmark score performs better in two cases as the LM does not consider the mediation effect tested in the PLS-SEM model analysis (Shmueli et al., 2019) (see Table 10). However, there is no predictive power for PES as the error is equal for the PLS-SEM and naive LM benchmark.

\section{Discussion}

\subsection{Factors Affecting Attitude towards ESs}

The study's first two hypotheses assessed the effects of ENC and ENK on ATT. The study findings support the argument that ENC $\left(f^{2}=0.106\right)$ and ENK $\left(f^{2}=0.081\right)$ have a significant and positive effect on the ATT among Malaysian youth. The effect of ENC and ENK on ATT for ES is small (Chin, 2010). This study finding is parallel to the studies by Maichum et al. (2016) and Mostafa (2006) that ENC and ENK affect ATT, respectively. The third, fourth, and fifth hypotheses attempted to assess the effect of ATT, SBN, and PBC on WTP ESs. The study findings support the argument that ATT ( $\left.f^{2}=0.054\right)$ has a significant but small positive effect on WTP, SBN $\left(f^{2}=0.011\right)$ has a small and significant effect on WTP, and PBC $\left(f^{2}=0.032\right)$ has a significant and small effect (Chin, 2010) on WTP ES among the Malaysian youth. The study results are supported by Maichum et al. (2016) and Yadav and Pathak (2017) that environmentally friendly product WTP is explained by ATT, SBN, and PBC.

The sixth hypothesis tested the effect of AOI on WTP. The study findings support the argument that AOI $\left(f^{2}=0.027\right)$ has a significant and positive effect on WTP among Malaysian youth. This result is supported by Carley et al. (2013). The study's seventh hypothesis attempted to test the effect of PMV on WTP. The study findings support the argument that PMV $\left(f^{2}=0.104\right)$ has a significant and small positive effect on WTP among Malaysian youth. This finding is supported by Lai et al. (2015). The study's eighth hypothesis tested the effect of WTP on PES. The study findings support the argument that WTP $\left(f^{2}=\right.$ 
0.004) has a significant, positive, but marginal effect on PES among Malaysian youth. This study finding is parallel to the findings by Yadav and Pathak (2017).

\subsection{Mediating Effects}

The next mediating hypothesis of $\mathrm{H}_{1 \mathrm{M}}$ investigated the mediating effect of ATT between ENC and WTP. The finding approves the meditating effect of ATT $(\beta=0.067, p=0.000)$ for the relationship between ENC and WTP for Malaysian youth. The findings are supported by several studies (Maichum et al., 2016; Yadav \& Pathak, 2016). $\mathrm{H}_{2 M}$ is about the meditating effect of ATT between ENK and WTP. The finding confirms the meditating effect of ATT $(\beta=0.059, p=0.000)$ for the relationship between ENK and WTP for ES. The finding is supported by Maichum et al. (2016).

$\mathrm{H}_{3 \mathrm{M}}$ is about the meditating effect of WTP between ATT and PES. The finding confirms the significant mediating effect of WTP $(\beta=0.014, p=0.004)$ for the relationship between ATT and PES. The support for the results is from the work of Yadav and Pathak (2017). Furthermore, $\mathrm{H}_{4 \mathrm{M}}$ tested the meditating effect of WTP between the relationship of SBN and PES. The finding confirms the mediating effect of WTP $(\beta=$ $0.007, p=0.020)$ for the relationship between SBN and WTP. The support for the study results is from Yadav and Pathak (2017). $\mathrm{H}_{5 \mathrm{M}}$ tested the mediating effect of WTP between PBC and PES. The finding confirms the meditating effect of WTP $(\beta=0.013, p=0.010)$ for the relationship between PBC and PES. Moreover, $\mathrm{H}_{6 \mathrm{M}}$ confirmed the mediating effect of WTP between AOI and PES. The finding confirms the meditating effect of WTP $(\beta=0.011, p=0.005)$ for the relationship between AOI and PES.

Moreover, $\mathrm{H}_{7 \mathrm{M}}$ tested the mediating effect of WTP between PMB and PES. The finding confirms the meditating effect of WTP $(\beta=0.020, p=0.003)$ for the relationship between PMB and PES. Nevertheless, WTP has a meditational effect between ATE, SUN, and PBC for PES (Yadav \& Pathak, 2017). The study results show the mediational effect of WTP for PMB and PES, AOI, and PES.

\subsection{Group Analysis}

The multiple-group analysis was performed to assess the effect of respondents' personal features such as gender, area, and education. The PLS multiple group analysis technique was employed to evaluate the effects of these characteristics. Study results offer pieces of evidence that gender does not affect the study paths, and there is no significant difference between study paths based on gender for the respondents who live in urban and rural areas. There is a significant difference between ATT and WTP for the respondents who live in urban and rural areas. For the other paths of the study, there is no significant difference based on the respondents' area of living.

Moreover, the effect of respondents' education is significantly different from ENC and ATT, ENK, and ATT for respondents who have low and high education. There is no significant difference for other paths of the study model based on the respondents' education.

\subsection{Predictive Assessment}


Model predictive assessment was performed with the PLSpredict. The comparison of RMSE scores reveals that the PLS-SEM analysis performs moderately better than the naïve LM analysis for the endogenous construct of WTP. For the endogenous construct PES, the PLS-SEM model has no predictive power that is better than the naïve LM benchmark.

\subsection{IPMA Analysis}

Next, this study evaluated the performance of PES with the factors of ENC, ENK, ATT, SBN, PBC, Al, PMV, and WTP. The most critical three factors for the performance of PES are ENC, ATT, and AOI. The fourth and fifth important factors for the performance of PES are PMB and WTP for ES.

\section{Conclusion}

Global environmental education is rising, and energy conservation, emission reduction, and environmentfriendly product adoption are on the rise. Our lifestyle and our transport mode are unsustainable (Rezvani et al., 2015). Individual mobility was on the rise in the past, and transportation remains a significant contributor to GHGs emissions. South Asian countries are known as the hub of people that use twowheelers (Eccarius \& Lu, 2020). The rise of individual mobility needs to be sustainable like the use of EVs or specifically individual mobility on the use of ES. Southeast Asians use two-wheelers for individual short distance travel (Rezvani et al., 2015). The use of two-wheelers is associated with the factors of weather, economy, and culture (Eccarius \& Lu, 2020). Youth are more inclined to use ES.

Malaysia is among the top ten markets for two-wheelers. Converting individual mobility usage of twowheelers to ES can promote environmental benefits that enable Malaysians to achieve SDGs 15. This paper investigated the consumer perspective of ES's WTP and PES among Malaysian youth from the TPB lenses and the extension by the factors of $\mathrm{AOI}$ and PMB. The results show that Malaysian youth are willing to purchase ES, but the actual purchase of ES is less but significant.

Local and national policy guidelines can play a significant role in the adoption of ES. The mobility demand is on the rise and significantly contributes to climatic issues (Lin et al., 2017). Policymakers need to balance mobility requirement and environmental issues. Offering subsidies like no road tax and zero import duty and reducing the production of combustion-based two-wheelers are among the options to facilitate the adoption of ES among Malaysian youth. The adoption of ES is socially promoted to reduce the use of conventional two-wheelers. Another relevant area that needs attention is the charging outlet or fuel stations for ES. The adoption of ES remains low if there is a lack of charging or fuel stations.

Finally, there should be a focus on behavioural change in the public. The attitude and preferences are considerably changed if the right and valid evidence are provided that ES can provide monetary and environmental benefits. The use of experiential marketing, long-term lease, and government incentive schemes positively affect the adoption of ES (Chen et al., 2018). Moreover, the manufacturing industry needs to determine the consumers' preference to understand their buying behaviour and enhance the ES 
features with reduced cost (Lin et al., 2017). An informed individual is always more inclined to use innovative and environmentally friendly products.

The associated limitations of this study are as follows. The consumers are different based on their personal attributes like willingness to experiment, innovativeness, and awareness. Future research may include these personal attributes to estimate the willingness to purchase ESs. The benefits can be realised on the actual use of the innovation. This cross-sectional study lacked the actual use of ES by consumers. Therefore, future research models may be apt to use the longitudinal study design to fully grasp the attributes of ES that influence the adoption of ESs. At the early stage of ES market, the government incentive role should be explored by future research. Besides that, innovation adoption is complex and requires the social-economic policy research to understand the adoption barrier like ES.

\section{Declarations}

\section{Ethics approval and consent to participate}

Local ethics committees (Universiti Malaysia Kelantan, Malaysia) ruled that no formal ethics approval was required in this particular case. This study has been performed in accordance with the Declaration of Helsinki. Written informed consent for participation was obtained from respondents who participated in the survey. For the respondents who participated the survey online (using google form), they were asked to read the ethical statement posted on the top of the form (There is no compensation for responding nor is there any known risk. In order to ensure that all information will remain confidential, please do not include your name. Participation is strictly voluntary and you may refuse to participate at any time) and proceed only if they agree. No data was collect from anyone under 16 years old.

\section{Consent to publish}

Not applicable

\section{Availability of data and materials}

All data generated or analysed during this study are included in this published article (Submitted with the Manuscript: additional supporting file)

\section{Competing interests}

The author(s) declare(s) that they have no competing interests.

\section{Funding}


Not applicable

\section{Authors' Contributions}

AAM contributed to the conception, research design, analyse and interpretation of data, and prepared the final draft. NRZ contributed to the research design, questionnaire design and data collection. $\mathrm{NH}$ contributed to the conception, design of the work and have drafted the manuscript.

\section{References}

1. Afroz, R. Masud, M.M. Akhtar, R., Islam, M.A. \& Duasa, J.B. (2015), Consumer purchase intention towards environmentally-friendly vehicles: an empirical investigation in Kuala Lumpur, Malaysia. Environmental Science and Pollution Research, 22: 16153-16163

2. Bennett, R. \& Vijaygopal, R., (2018), Consumer attitudes towards electric vehicles: Effects of product user stereotypes and self-image congruence, European Journal of Marketing, 52(3/4): 499-527

3. Carley, S. Krause, R.M., Lane, B.W. \& Graham, J.D., (2013), Intent to purchase a plug-in electric vehicle: A survey of early impressions in large US cities, Transportation Research Part D, 18: 39-45.

4. Cain, M. K., Zhang, Z., and Yuan, K.-H. (2017). Univariate and multivariate skewness and kurtosis for measuring nonnormality: Prevalence, influence, and estimation. Behaviour Research Methods,49(5): 1716-1735.

5. Chen, H-S. Tsai, B-K. \& Hsieh, C-M. (2018). The effects of perceived barriers on innovation resistance of hydrogen-electric motorcycles. Sustainability.10 (1933). DOI:10.3390/su10061933

6. Chin, W.W. (2010). "How to write up and report PLS analyses," In Vinzi, V.E., Chin, W.W., Henseler, J. and Wang, H. (Eds), Handbook of Partial Least Squares. Springer, Berlin.

7. DellaValle, N. \& Zubaryeva, A. (2019). Can we hope for a collective shift in electric vehicle adoption? Testing salience and norm-based interventions in South Tyrol, Italy. Energy Research \& Social Science. 55. 46-61. https://doi.org/10.1016/j.erss.2019.05.005

8. Eccarius, T. \& Lu, C. (2020). Powered two-wheelers for sustainable mobility: A review of consumer adoption of electric motorcycles, International Journal of Sustainable Transportation, 14:3, 215-231

9. Henseler, J., Ringle, C.M. and Sarstedt, M. (2015), A new criterion for assessing discriminant validity in variance-based structural equation modeling, Journal of the Academy of Marketing Science, 43(1), 115-135.

10. Henseler, J., Ringle, C., \& Sinkovics, R. (2009). The use of partial least squares path modeling in international marketing. In: Sinkovics, R. R. / Ghauri, P. N. (eds.), Advances in International Marketing, 20, 277-320.

11. Hair, J.F., Risher, J. J., Sarstedt, M., and Ringle. C. M. (2019). When to use and how to report the results of PLS-SEM. European Business Review. 31(1). 2-24. 
12. Higueras-Castillo, E. Molinilo, S., Cosa-Stefaniak, J., A., \& Liebana-Cabanillas, F. (2019). Perceived value and customer adoption of electric and hybrid vehicles. Sustainability, 11(4956), DOI:10.3390/su11184956

13. Jone, L. R., Cherry, C. R., Vu, T. A., \& Nguyen, Q. N. (2013). The effect of incentives and technology on the adoption of electric motorcycles: A stated choice experiment in Vietnam. Transportation Research Part $A$, 57: 1-11.

14. Lai, I., K., W., Liu, Y., Sun, X., Zhang, H \& Xu, W. (2015). Factors Influencing the Behavioural Intention towards Full Electric Vehicles: An Empirical Study in Macau. Sustainability. 7, 12564-12585. DOI:10.3390/su70912564

15. Leavy, P. Z., Drossinos, Y., \& Thiel, C. (2017). The effect of fiscal incentives on market penetration of electric vehicles: A pairwise comparison of the total cost of ownership. Energy Policy, 105, 524-533. http://dx.doi.org/10.1016/j.enpol.2017.02.054

16. Maichum, K., Parichatnon, S. \& Peng, K.-C. (2016) Application of the Extended Theory of Planned

17. Behavior Model to Investigate Purchase Intention of Green Products among Thai Consumers, Sustainability 8(1077): 1-20. DOI:10.3390/su8101077

18. Mostafa, M. (2006). Antecedents of Egyptian Consumers' Green Purchase Intentions. Journal of International Consumer Marketing, 19(2): 97-126.

19. Peng, D.X. and Lai, F. (2012). Using partial least squares in operations management research: A practical guideline and summary of past research. Journal of Operations Management. 30(6): 467480.

20. Podsakoff, P.M.; MacKenzie, S.B.; Lee, J.Y.; and Podsakoff, N.P. (2003). Common method biases in behavioral research: A critical review of the literature and recommended remedies. Journal of Applied Psychology. 88 (5), 879-903.

21. Peters, A. \& Dutschke, E. (2014). How do Consumers Perceive Electric Vehicles? A Comparison of German Consumer Groups, Journal of Environmental Policy \& Planning, 16:3, 359-377.

22. Razak, M. I. M., Yusof, A. M., Mashahadi, F., Alias, Z., \& Othman, M., Z. (2014).

23. Intention to purchase Hybrid cars in Malaysia: An overview. International Journal of Economics, Commerce, and Management. II (10).

24. Rezvani, Z., Jansson, J. \& Bodin, J. (2015). Advances in consumer electric vehicle adoption research: A review and research agenda. Transportation Research Part D, 34: 122-136.

25. Ringle, C. M., and Sarstedt, M. (2016). Gain more insight from your PLS-SEM results. The importanceperformance map analysis. Industrial Management \& Data Systems. 116(9), 165-1886.

26. Shumeli, G. Sarstedt, M., Hair. J. F., Cheah, J-H, Ting, H., Vaithilingam, S., \& Ringle, C. M. (2019). Predictive model assessment in PLS-SEM: Guidelines for using PLSpredict. European Journal of Marketing. DOI 10.1108/EJM-02-2019-0189

27. Tu, J. \& Yang, C. (2019). Key factors influencing consumers' purchase of electric vehicles. Sustainability. 11(3863), DOI:10.3390/su11143863 
28. Yadav, R. and Pathak, G.S. (2016). Young consumers' intention towards buying green products in a developing nation: Extending the theory of planned behaviour. Journal of Cleaner Production. 135, 732-739. http://doi.org/10.1016/j.jclepro.2016.06.120

29. Yadav, R. and Pathak, G.S. (2017). Determents of consumers' green purchase behaviour in a developing nation: Applying and extending the theory of planned behaviour. Ecological Economics. 134 (C), 114-122.

\section{Annexure}

Annexure. Survey Instrument 
Code Items

EC1 I am very concerned about the state of the world's environment

EC2 I am willing to reduce my consumption to help protect the environment

EC3 Major social changes are necessary to protect the natural environment

EC4 Major political change is necessary to protect the natural environment

EC5 I am a person who does what is right for the environment, even when it takes more time or costs more money

EK1 I prefer to check the eco-labels and certifications on green products before purchase

EK2 I want to have a deeper insight into the inputs, processes and impacts of products before purchase

EK3 I would prefer to gain substantial information on green products before purchase

EK4 I know how to select products and packages that are environmentally safe

EK5 I understand the environmental phrases and symbols on the product package

AT1 I believe that ESs are: a good thing, beneficial, attractive

AT2 My attitude towards ESs are favourable

AT3 I believe that ESs can reduce greenhouse gas emission

AT4 I think that purchasing ESs is a good idea

AT5 I think that purchasing ESs is safe

SN1 My family think that I should purchase ES over a petrol or diesel vehicle

SN2 My close friends think that I should purchase ES over a petrol or diesel vehicle

SN3 Most people who are important to me think I should purchase ES over a petrol or diesel vehicle

SN4 Most people who are important to me usually view me as being like the typical person who prefers an ES over a petrol or diesel vehicle

SN5 People who know me think of me as someone who would be happy to buy an ES

PB1 I am confident that I can purchase ES rather than petrol or diesel vehicle when I want

PB2 I see myself as capable of purchasing ES in future

PB3 I have resources, time and willingness to purchase ES

PB4 There are likely to be plenty of opportunities for me to purchase ES

PB5 Purchasing ES would be entirely within my control

Al1 Fuel economy is one of the most important attributes of ES 
Al2 The appearance of ES is one of the most important attributes

Al3 Space is one of the most important attributes of ES

Al4 Sticker price is one of the most important attributes of ES

Al5 Safety is one of the most important attributes of ES

MB1 Driving ES will help me spend less on fuel

MB2 Driving ES will give me other government incentives

MB3 Driving ES will help me spend less on maintenance

MB4 Driving ES will help me spend less on insurance and road tax

MB5 Considering all costs, driving ES is no more expensive than driving conventional motorcycles

WP1 Provided the price of an ES was reasonable and within my budget, I would be very willing to buy an ES

WP2 Provided the price of an ES was reasonable and within my budget, I would seriously consider buying an ES

WP3 Provided the price of an ES was reasonable and within my budget, I would be enthusiastic about the prospect of buying an ES

WP4 Provided the price of an ES was reasonable and within my budget, I would consider it important to think carefully about buying an ES

PES Do you have an ES?

\section{Figures}




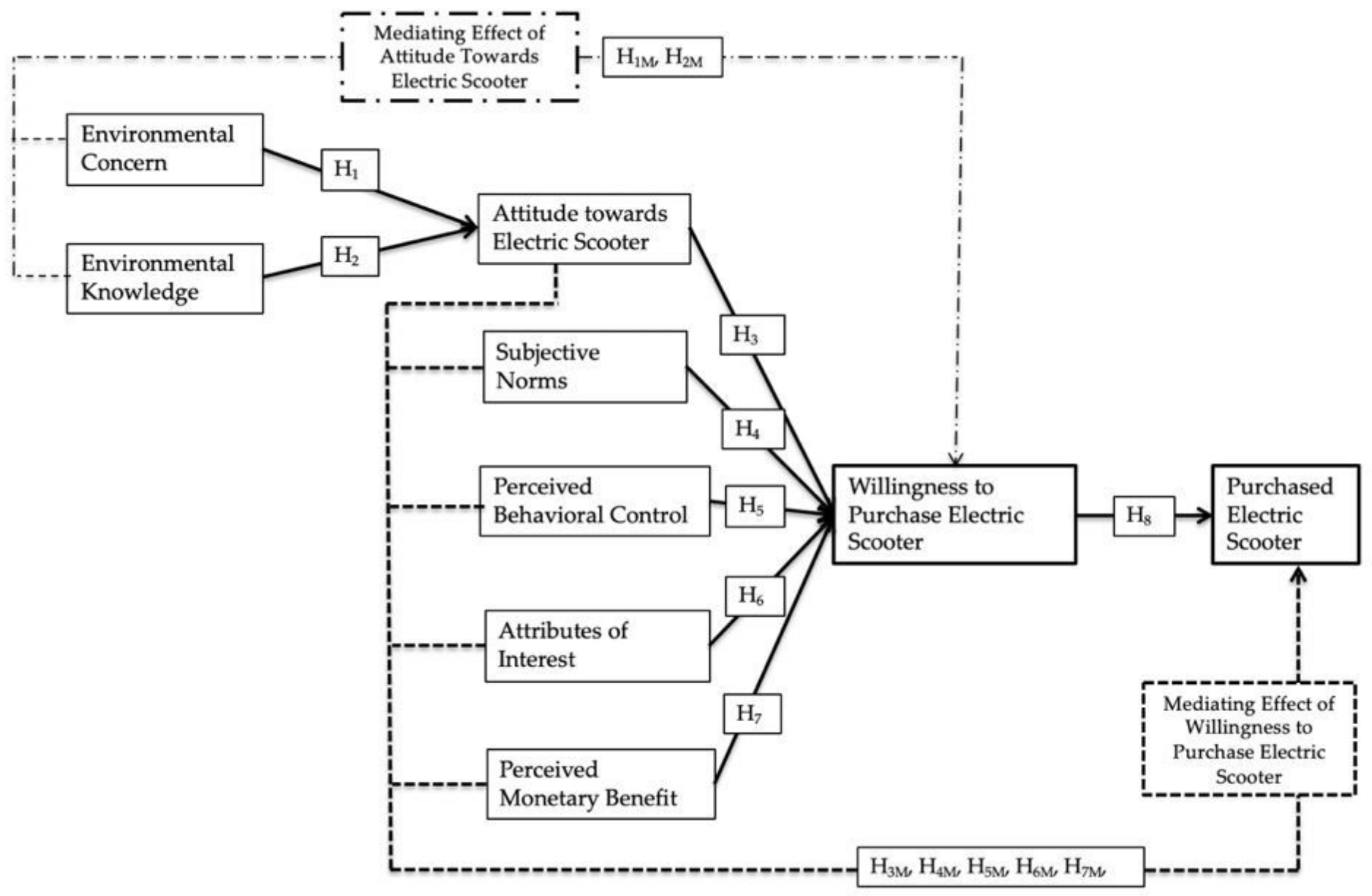

Figure 1

Research Framework 


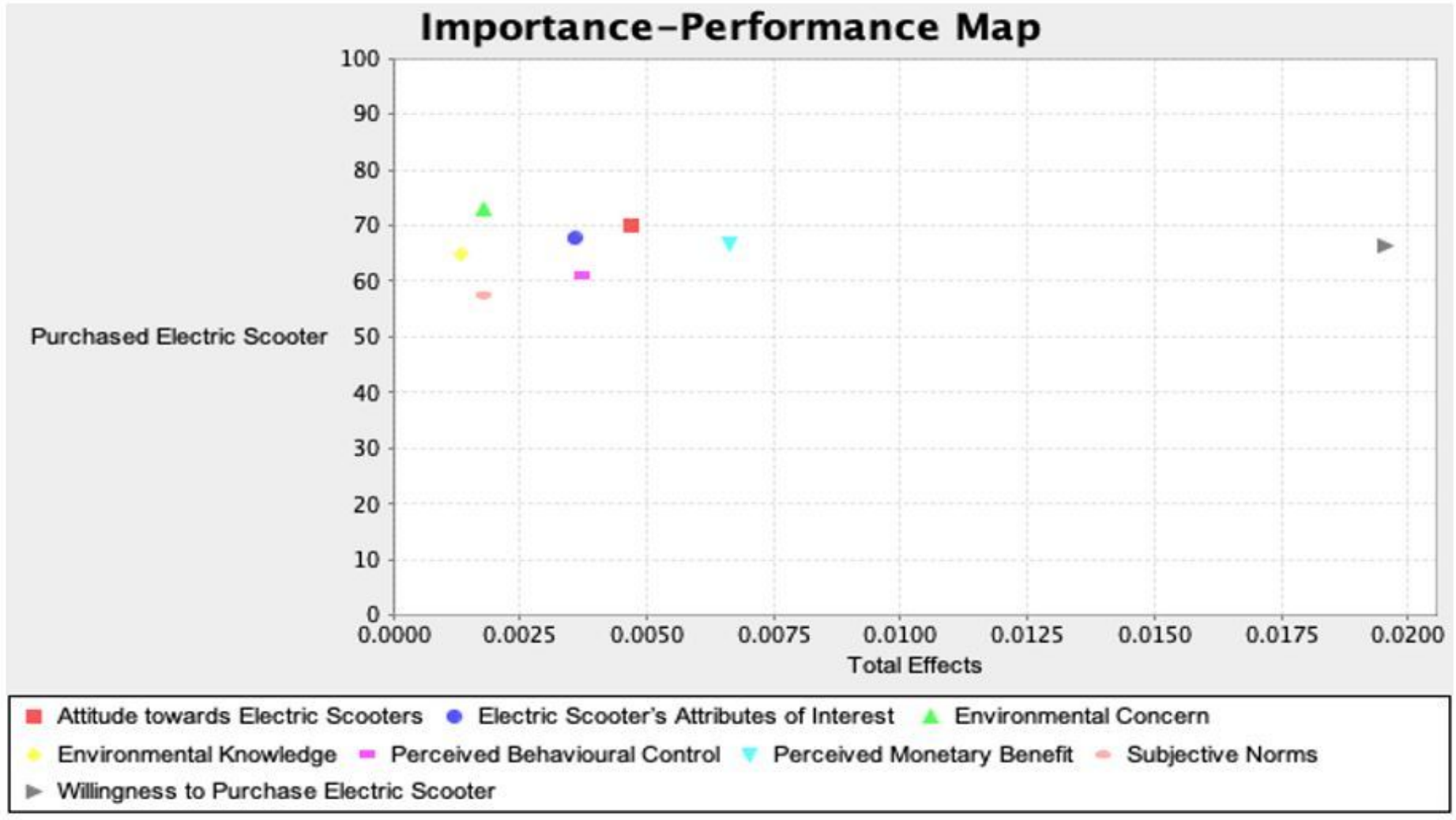

Figure 2

Importance Performance Map
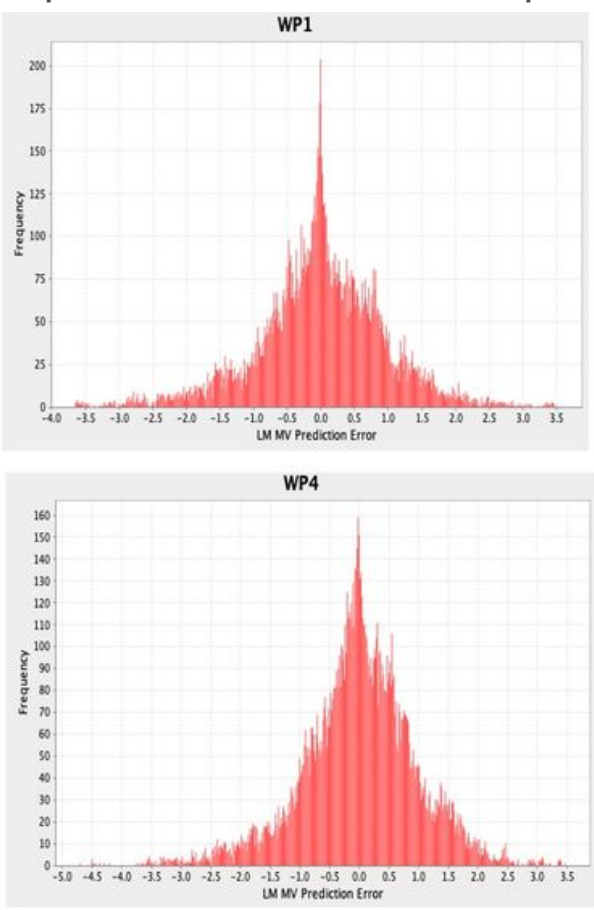
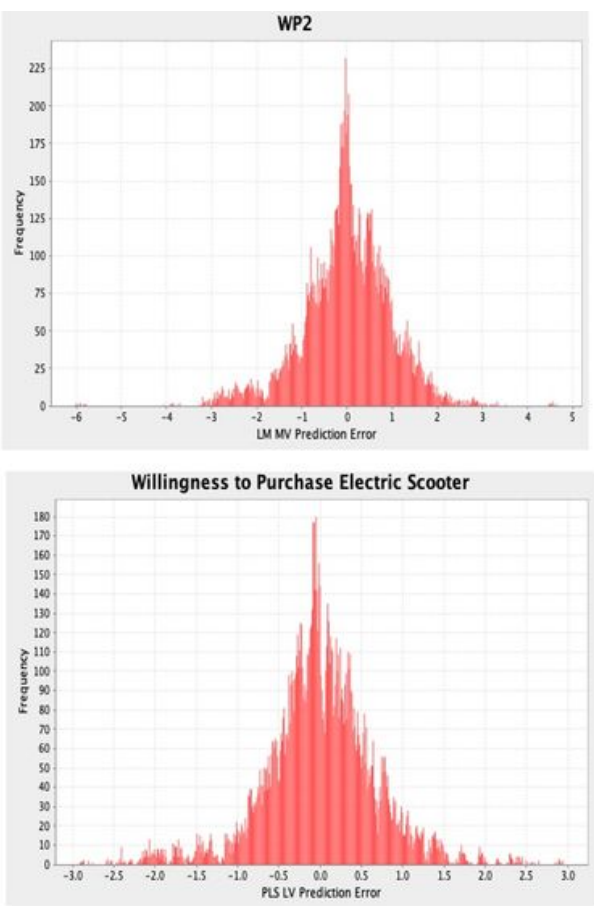
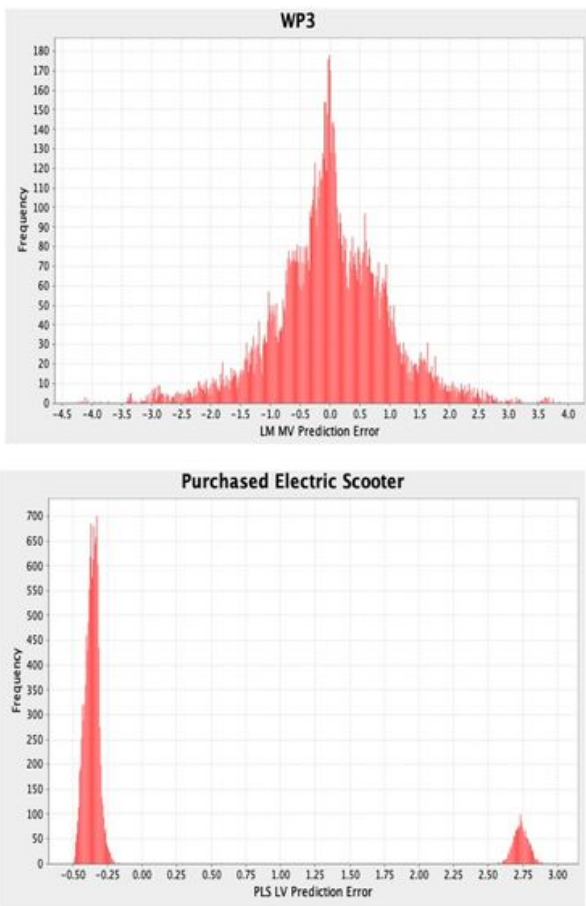

Figure 3 
Distributing of Prediction Error

Page $32 / 32$ 